\title{
Top 10 Dietary Supplements of Korean Adults from the 4th Korea National Health and Nutrition Examination Survey

\author{
Hyun Ah Park*
}

Department of Family Medicine, Seoul Paik Hospital, Inje University College of Medicine, Seoul, Korea

The aim of this study is to assess the prevalence, types, and trends of dietary supplement (DS) use. We analyzed the Dietary Supplement Questionnaire data of Korean aged 19 years old or older from the Nutrition Survey of the 4th Korea National Health and Nutrition Survey. Each reported DS was coded based on ingredients according to the 2010 Korean Food and Drug Administration Notification. The prevalence (standard error) of current DS use was 20.6\% (0.7) for men, 32.2\% (0.7) for women. Those with DS use for longer than two weeks during previous one year were $27.2 \%(0.7)$, and $40.2 \%(0.8)$, for men and women respectively. Vitamin mineral supplement $\left(221.6 / 10^{3}\right.$ persons) was the most frequently consumed DS in Korean adults. The trend for DS use in Korean adults is changing as well as increasing.

Keywords: Korea National Health and Nutrition Survey; Dietary Supplements

\section{INTRODUCTION}

The sale of dietary supplements (DS) has been steadily increasing in Korea and the popular DS varies from time period to time period. ${ }^{1)}$ We already reported the most frequently consumed DS and the related factors from the 2005 Korea National Health and Nutrition Survey (KNHANES). ${ }^{2)}$ This study is to assess the prevalence of DS use, and the types of DS taken from the 4th survey, updating our previous findings.

Received: April 18, 2011, Accepted: May 3, 2011

${ }^{*}$ Corresponding Author: Hyun Ah Park

Tel: 82-2-2270-0097, Fax: 82-2-2267-2030

E-mail:drparkhyunah@gmail.com

Korean Journal of Family Medicine

Copyright (C) 2011 The Korean Academy of Family Medicine

() This is an open-access article distributed under the terms of the Creative Commons Attribution Non-Commercial License (http://creativecommons.org/licenses/by-nc/3.0) which permits unrestricted noncommercial use, distribution, and reproduction in any medium, provided the original work is properly cited.

\section{METHODS}

We used the Dietary Supplement Questionnaire data of Korean aged 19 years old or older from the Nutrition Survey of the 4th KNHANES. Dietary Supplement Questionnaire was composed of two main components. First part included questions about the consumption experience of DS for longer than 2 weeks during previous one year, and the second part was the identification of the types of DS taken currently. Trained interviewers recorded each supplement' brand name and manufacturer from the label up to four kinds.

Each reported DS was mainly coded based on ingredients according to the 2010 Korean Food and Drug Administration (KFDA) Notification. ${ }^{3)}$ To simplify classification, single vitamin, multiple vitamin, single mineral, multiple mineral, vitamin/ mineral combination were all categorized into vitamin/mineral supplements. Aloe leaf and aloe gel were categorized as aloe, Ginseng and red Ginseng as Ginseng, and glucosamine and mucopolysacchride (chondroitin) as glucosamine/chondroitin. Ingredients unlisted in the KFDA notification such as ursode- 
soxycolic acid (classified as a drug by KFDA) and shark cartilage were categorized into new categories.

Druginfo (www.druginfo.co.kr), Kimsonline (www.kimsonline.co.kr), manufacturer's and distributor's websites were searched to identify the constituents of each DS. 104 DS (0.2\%) of which ingredients could not be identified were included in prevalence estimations but excluded from the top 10 list.

6,708 Korean adult men and 9,695 women aged 19 years old or older representing 37,996,253 Koreans were included in the analysis. Descriptive analyses were performed with STATA ver. 10 (2007; Stata Co., College Station, TX, USA) to incorporate sampling weight (wt_ntr) considering the multistage probability sampling design of KNHANES and nonresponse. The 10 most commonly taken DS types were reported according to sex and age groups.

\section{RESULTS}

Prevalence (standard error) of current DS use was 20.6\% (0.7) for men, 32.2\% (0.7) for women. Proportion of adults taking one supplement was $17.9 \%(0.4)$, two supplements $5.9 \%$ (0.3), three supplements $1.9 \%$ (0.1), and four or more supplements $0.8 \%$ (0.1). Those with DS consumption for longer than two weeks during previous one year were $27.2 \%$ (0.7) for men and $40.2 \%$ (0.8) for women respectively (data not shown).

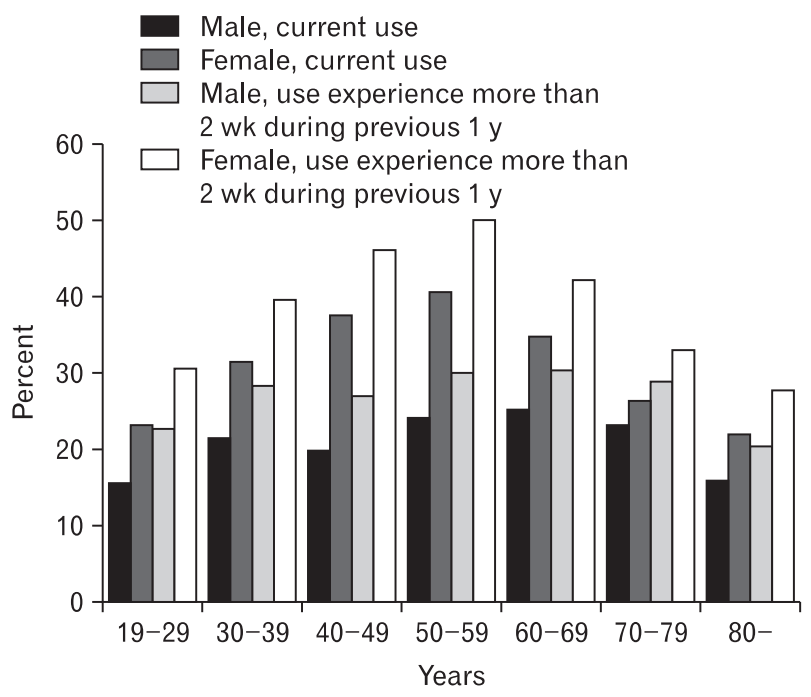

Figure 1. Use of dietary supplements in Korean adults according to sex and age.
The consumption rate was higher in women than in men across all age groups (Figure 1).

The top 10 DS among Korean adults were listed in Table 1. Vitamin mineral supplement $\left(221.6 / 10^{3}\right.$ persons $)$ was the most frequently consumed DS in all sex and age groups followed by omega 3 fatty acids $\left(51.0 / 10^{3}\right.$ persons for all Korean adults), glucosamine/chondroitin $\left(39.1 / 10^{3}\right.$ persons $)$, and gamma linolenic acid ( $15.5 / 10^{3}$ persons) (data not shown). Ginseng was in the 4th place for men and 6th place for women. There was a significant relationship between sex, age, and DS type. Ursodeoxycolic acid was in the top 10 list only in young and middle aged male groups.

\section{DISCUSSION}

This study reveals the top 10 DS used by Korean adults. The prevalence of DS use increased from $25.8 \%$ in the 2005 KNHANES to $33.8 \%$ in the 4 th KNHANES. There has been qualitative as well as quantitative change. Although the vitamin mineral supplements kept its 1st rank, other DS moved up and down in the popular DS list. Although Glucosamine/chondroitin fell from the rank of 2 nd place in 2005 survey to the rank of 3rd place in the 4th survey, the absolute number of adults taking the DS increased from $25.4 / 10^{3}$ persons to $39.1 / 10^{3}$. Most of all, the use of omega 3 fatty acid (9.5 to 51.0) and gamma linolenic acid (2.9 to 15.5) increased by five times during two survey periods.

For more than half of DS use, the very first decision to take DS was encouraged by the recommendations from family and friends and commercial advertisements while only $7 \%$ of DS use was promoted by advice from their physicians. ${ }^{4)}$ Since one third of DS users consume more than two supplements together, safety concern such as overdose and interactions with prescribed medication should be considered.

Limitations of our study are as followed. Our study did not include traditional modified foods or herbal medicine; therefore it might underestimate their prevalence in Korea. The KFDA notification can neither encompass the entire variety of DS consumed by Korean nor be the standardized classification of non-vitamin non-mineral supplements yet. Therefore, it is very difficult to make direct comparisons between countries and different time periods. However, this study is unique in that 
Table 1. Prevalence (per 1,000 persons) of dietary supplements usage categories by Korean adults by sex and age groups.*

\begin{tabular}{|c|c|c|c|c|c|c|c|c|}
\hline \multirow{3}{*}{$\begin{array}{c}\text { Rank } \\
1\end{array}$} & \multicolumn{8}{|c|}{ Male } \\
\hline & $18-39 y$ & \multicolumn{2}{|r|}{$40-64$ y } & \multicolumn{3}{|c|}{ Over 65 y } & \multicolumn{2}{|l|}{ Total } \\
\hline & $\begin{array}{l}\text { Vitamin/ } \\
\text { mineral supplements }\end{array}$ & 156.3 & $\begin{array}{l}\text { Vitamin/ } \\
\text { mineral supplements }\end{array}$ & 174.5 & $\begin{array}{l}\text { Vitamin/ } \\
\text { mineral supplements }\end{array}$ & 172.3 & $\begin{array}{l}\text { Vitamin/ } \\
\text { mineral supplements }\end{array}$ & 166.1 \\
\hline 2 & Omega 3 fatty acid & 23.3 & Omega 3 fatty acid & 39.0 & Omega 3 fatty acid & 46.3 & Omega 3 fatty acid & 32.8 \\
\hline 3 & Ginseng & 9.9 & Glucosamine/chondroitin & 21.7 & $\begin{array}{l}\text { Glucosamine/ } \\
\text { chondroitin }\end{array}$ & 28.9 & $\begin{array}{l}\text { Glucosamine/ } \\
\text { chondroitin }\end{array}$ & 15.1 \\
\hline 4 & Chlorella/spiriluna & 5.7 & Ginseng & 13.8 & Ginseng & 19.2 & Ginseng & 12.6 \\
\hline 5 & Glucosamine/chondroitin & 5.4 & Gamma linolenic acid & 8.6 & Royal jelly & 7.6 & Gamma linolenic acid & 6.4 \\
\hline 6 & Gamma linolenic acid & 4.4 & $\begin{array}{l}\text { Chitosan/ } \\
\text { chito-oligosacchride }\end{array}$ & 7.3 & Chlorella/spiriluna & 6.6 & Chlorella/spiriluna & 6.2 \\
\hline 7 & Aloe & 3.7 & Aloe & 6.8 & Gamma linolenic acid & 5.8 & Aloe & 5.0 \\
\hline 8 & Yeasts & 3.0 & Chlorella/spiriluna & 6.6 & $\begin{array}{l}\text { Chitosan/ } \\
\text { chito-oligosacchride }\end{array}$ & 5.1 & $\begin{array}{l}\text { Chitosan/ } \\
\text { chito-oligosacchride }\end{array}$ & 4.2 \\
\hline 9 & Ursodeoxycholic acid & 2.4 & Yeasts & 5.4 & Yeasts & 3.8 & Yeasts & 4.1 \\
\hline 10 & Propolise & 1.3 & Ursodeoxycholic acid & 4.1 & Aloe & 3.0 & Ursodeoxycholic acid & 3.0 \\
\hline \multicolumn{9}{|c|}{ Female } \\
\hline Rank & $18-39 y$ & & $40-64 y$ & & Over 65 y & & Total & \\
\hline 1 & $\begin{array}{l}\text { Vitamin/mineral } \\
\text { supplements }\end{array}$ & 261.8 & $\begin{array}{l}\text { Vitamin/mineral } \\
\text { supplements }\end{array}$ & 294.0 & $\begin{array}{l}\text { Vitamin/ } \\
\text { mineral supplements }\end{array}$ & 201.1 & $\begin{array}{l}\text { Vitamin/ } \\
\text { mineral supplements }\end{array}$ & 266.1 \\
\hline 2 & Omega 3 fatty acid & 28.8 & Omega 3 fatty acid & 88.4 & $\begin{array}{l}\text { Glucosamine/ } \\
\text { chondroitin }\end{array}$ & 76.6 & Omega 3 fatty acid & 57.7 \\
\hline 3 & Gamma linolenic acid & 14.4 & Glucosamine/chondroitin & 79.3 & Omega 3 fatty acid & 50.6 & $\begin{array}{l}\text { Glucosamine/ } \\
\text { chondroitin }\end{array}$ & 48.9 \\
\hline 4 & Chlorella/spiriluna & 12.2 & Gamma linolenic acid & 38.1 & Aloe & 12.3 & Gamma linolenic acid & 23.3 \\
\hline 5 & Ginseng & 9.5 & Aloe & 16.4 & Gamma linolenic acid & 6.8 & Chlorella/spirulina & 12.8 \\
\hline 6 & Glucosamine/chondroitin & 7.3 & Chlorella/spiriluna & 16.3 & Ginseng & 9.0 & Ginseng & 10.6 \\
\hline 7 & Yeasts & 6.0 & Ginseng & 12.3 & Lutein & 5.4 & Aloe & 10.3 \\
\hline 8 & Coenzyme Q10 & 4.1 & Yeasts & 11.5 & Yeasts & 5.2 & Yeasts & 8.2 \\
\hline 9 & Colostrum & 3.5 & Shark cartiliage & 6.5 & Shark cartiliage & 5.1 & $\begin{array}{l}\text { Chitosan/ } \\
\text { chito-oligosaccharide }\end{array}$ & 3.9 \\
\hline 10 & Aloe & 3.1 & $\begin{array}{l}\text { Chitosan/ } \\
\text { chito-oligosacchride }\end{array}$ & 6.1 & $\begin{array}{l}\text { Chitosan/ } \\
\text { chito-oligosacchride }\end{array}$ & 5.0 & Shark cartilage & 3.8 \\
\hline
\end{tabular}

${ }^{*}$ One hundred and four dietary supplements were excluded due to inappropriate information. Classification is based mainly on 2010 Korean Food \& Drug Administration notification. ${ }^{3)}$ Multiple answers up to four supplements were allowed.

it describes the types of current DS use from a representative sample of Korean adults. Until now, most reports on consumed DS type were mainly based on sales data.

There are reports that many people do not inform their physicians of their DS consumption ${ }^{5,6)}$ Clinicians should understand that considerable proportion of patients take DS and pay attention to the expanding and changing trend of the DS use among Korean adults. 


\section{REFERENCES}

1. Korea Food \& Drug Administration. 2009 Health functional food production statistics data. Seoul: Korea Food \& Drug Administration; 2010.

2. Yi HH, Park HA, Kang JH, Kang JH, Kim KW, Cho YG, et al. What types of dietary supplements are used in Korea? Data from the Korean National Health and Nutritional Examination Survey 2005. Korean J Fam Med 2009;30:93443.

3. Korea Food \& Drug Administration. Manual for KFDA notification (No. 2010-86) health functional food. Seoul: Korea Food \& Drug Administration; 2011.
4. Korea Centers for Disease Control and Prevention. The third Korea National Health \& Nutrition Examination Survey (KNHANES III), 2005: Nutrition survey (II). Seoul: Korea Centers for Disease Control and Prevention; 2006.

5. Eisenberg DM, Davis RB, Ettner SL, Appel S, Wilkey S, Van Rompay M, et al. Trends in alternative medicine use in the United States, 1990-1997: results of a follow-up national survey. JAMA 1998;280:1569-75.

6. Singh BB, Vinjamury SP, Der-Martirosian C, Kubik E, Mishra LC, Shepard NP, et al. Ayurvedic and collateral herbal treatments for hyperlipidemia: a systematic review of randomized controlled trials and quasi-experimental designs. Altern Ther Health Med 2007;13:22-8. 